\title{
Research on Decorative Design of Porcelain Censers in Song Dynasty
}

\author{
Yihong Yuan ${ }^{1}$ Xuemei Liu ${ }^{1, *}$ \\ ${ }^{1}$ South China University of Technology, Guangzhou, Guangdong, China \\ *Corresponding author.Email: yhyuan@scut.edu.cn
}

\begin{abstract}
The Song Dynasty was the golden age of Chinese incense culture. Incense burning had become an indispensable part of life. Therefore, a rich variety of cencers was born. Among them, porcelain cencers are the most artistic. This article explores the decorative art of the Song Dynasty porcelain censers from the characteristics of the Song Dynasty porcelain censer decoration (glaze color, techniques, patterns), scientific interest and artistic style.
\end{abstract}

Keywords: Porcelain censers, Decorative features, Neo-Confucianism in Song Dynasty, Artistic style.

\section{INTRODUCTION}

The Chinese censer culture has a long history. In thousands of years of historical and cultural evolution, the shape, glaze, decoration, function and other artistic characteristics of the censers have all evolved along with the changes in the political economy, social culture, and aesthetic appeal of the dynasty. From the Shang and Zhou dynasty "ding", which was only used to store food and charcoal for heating, to the Han censer used to deodorize lavender, then, the idea of immortals and the introduction of Buddhism turned the censer into a tool for worshipping the gods and the Buddha. Li Bai's "日照香炉生紫烟 (The Xianglu Peak gave rise to purple haze under the sunlight)" is the best explanation. Finally, in the Song Dynasty, with the implementation of the policy of "emphasizing literature and restraining martial arts", the censer not only had practical functions, but also became the beloved object of literati who "红袖添香夜 读书 (is accompanied by young and beautiful women when he is studying)", giving them a sense of elegance and taste.

Ceramic decoration art is an art that integrates social aesthetics, ingenious techniques, and exquisite craftsmanship. It has both material elements and spiritual baptism, and has a very high aesthetic appeal. In fact, there have been richer decorations since primitive ceramics. After various generations of exploration and innovation, more mature decoration

*Fund: National Social Science Foundation (Project No.: 17BZX118) techniques were formed in the Song Dynasty. They were applied to various ceramic utensils, even censers. The craftsmen combined social fashions and aesthetic tastes to create many exquisite decorative techniques. They complemented each other and applied to the censers, making them integrate the beauty of shape, decoration and theme, and fully demonstrate the pursue of perfection of Song people.

\section{SONG DYNASTY PORCELAIN CENSERS}

Mr. Chen Yin'ge once said: "The culture of the Chinese nation has evolved over thousands of years and was at a peak between the two Songs" [1]. Based on the above, it can be found that the culture of the Song Dynasty was so brilliant and splendid that it occupies a very high position in Chinese history and culture. In the Song Dynasty, with the maturity of the porcelain industry and the popularization of incense culture, the design of censers was promoted and even reached its peak. With the five famous kilns of Guan, $\mathrm{Ge}, \mathrm{Ru}$, Ding and Jun as the main body, and supplemented by other local kilns, the production scale of ceramic censers was unprecedented. It can be said that the porcelain censer of Song Dynasty represents the artistic spirit of Song Dynasty porcelain.

The incense culture of the Song Dynasty is one of the indispensable tastes in the social life of the Song Dynasty. In Song Dynasty Wu Zimu's "Menglianglu": "Burning incense and boiling tea, hanging pictures 
and flower arrangements, four kinds of meddling, not suitable for all the families." [2] It can be imagined how many people admired burning incense at that time and how high the development of incense culture reached. Incense as one of the "four kinds of meddling" needs the aid of utensils, the design of the censers derived from it is endless and varied. At the same time, under the influence of the policy, the number of literati and poets gradually increased, and the "elegant" social fashion was formed in the Song Dynasty. Based on this, the design of the porcelain censers of the Song Dynasty retreated from the graceful, luxurious and magnificent style of the Tang Dynasty, and gradually moved towards the style of simple and elegant, pure and natural, and pursued the natural and elegant beauty of the censers through the characteristics of glaze, shape, and decoration.

\section{DECORATIVE FEATURES OF PORCELAIN CENSERS IN SONG DYNASTY}

\subsection{Glaze Color}

Glaze color is an important element of ceramic art, and its own characteristic is the best decoration for ceramics. The Song Dynasty pursued the aesthetic fashion of "the harmony between man and nature"; the Song people pursued the aesthetic tendency of "heavenly craftsmanship and freshness, sparse and refined"; they also pursued the best state of "clear water out of hibiscus and natural carving". Based on these aesthetic connotations, the design of the censers in the Song Dynasty did not rely on the gorgeous glaze color but relied on the crystal clear glaze and the elegant glaze color to show a fresh and elegant beauty, showing the effect of "colorless than colored". Because of this, the glaze decorations of five famous kilns that last forever have been formed. Taking the two-eared bowl-like censer made in the official kiln ("Figure 1") as the example, the overall glaze is pinkish blue, with a simple and elegant texture, a jade-like texture, and an ancient and gentle texture. The ingenious opening looks like a pattern formed by cracking ice, which is very beautiful. So why did it show such an effect? In fact, it is because of the temperature, the glaze shrinkage, and the embryo body shrinkage speed that different ice-like patterns are formed, which are uncontrollable. It is precisely because of this unpredictability that it embodies the aesthetic realm of "composing poems without history, but creating plain and difficult", consistent with the Song people's pursuit of the unity of nature and man.

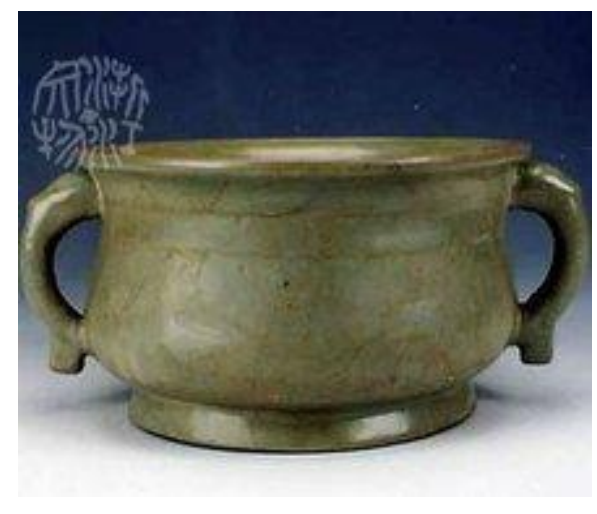

Figure 1 Official kiln, two-eared bowl-like censer.

The censers of the Song Dynasty also pursued the creative principle of "made in nature and bored with human will", and pursued natural craftsmanship. It can be seen from the naming of the glaze colors, grape purple, ivory white, beeswax yellow, etc. The names of these images are the best expression of nature. In order to reflect this natural color, the glaze decoration method of the censers is divided into two glazing methods - thick glaze and thin glaze. They show different characteristics in the glaze decoration of the incense burner: the thick glaze embodies the sense of simplicity, vigorousness, deep solemnity, and a return to the original, while the thin glaze shows a transparent, bright, pure and elegant model. All in all, the glaze color is natural, simple and elegant, and has high artistic aesthetic value.

\subsection{Techniques}

Throughout the entire development history of the censers, the artisans of the past generations have made the techniques mature through continuous study and innovating craftsmanship. Different techniques have formed various shapes, decorations, and themes, which ultimately constitute the historical precipitation of each period.

The decorative methods of the Song Dynasty censers mainly include printing, engraving, scratching, and picking, which can be used alone or combined with each other on the same utensil. The most worth mentioning is the decorative technique of Yaozhou kiln celadon carvings. The tools used are different from other kilns. They use iron knives and side knives to cut. The techniques of using knife are strong and swift, without any muddling. The overall effect is like a relief. It has a three-dimensional effect. Taking the Yaozhou kiln celadon carved peony pattern three-legged icenser as an example ("Figure $2 ")$, it is $10.3 \mathrm{~cm}$ high and $12 \mathrm{~cm}$ in diameter. The furnace mouth extends outwards, the furnace body is 
oblate, with three short animal feet underneath, the neck is carved with peony petals, and the belly is carved with peony leaves. With green glaze, the color of the glaze is dense and sparse with the nicks, and the color is suitable. The lines are free and flowing with images, full of three-dimensionality. However, the carving technique of Ding kiln white porcelain is just the opposite. The tire is thin and delicate, so it must be carved with a double-line knife. The carving is shallow and simple, slowly and steady, and the lines presented have a sense of real and virtual. If Yaozhou kiln is famous for its vigor and strength, then Ding kiln is quiet and elegant and attractive. The two kilns present the different carving styles of Song Dynasty censers with similar decoration techniques, reflecting the Song people's love for bright and lively, but also for the elegant and soft aesthetic taste. In short, the continuous development and innovation of censer decoration techniques not only reflects the mature and superb skills of the craftsmen, but also highlights the characteristics of the artistic language of this dynasty.

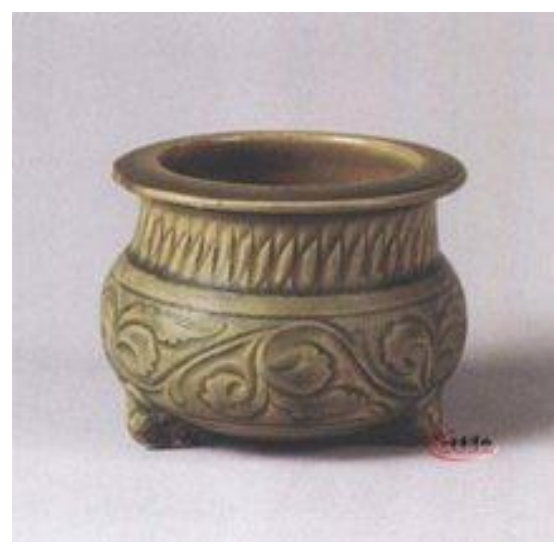

Figure 2 Yaozhou kiln three-legged censer with green glaze carved with peony pattern.

\subsection{Patterns}

The decorative art of the porcelain censers in the Song Dynasty pursues natural, mature and exquisite decorative techniques, and rich decorative subjects. Under the unique aesthetic requirements of Song people, a unique decorative fashion has been formed. In fact, the social fashion and decorative art of the Song Dynasty are both external and internal. While the social fashion has influenced the design of the porcelain censers, the decoration of the porcelain censers also reflects the living environment of the Song Dynasty and people's aesthetic taste.

On the one hand, the patterns of the censers are symbols of auspiciousness and beauty: for example, peony has the meaning of "flowers blooming and rich and honorable". The lotus flower is "out of silt but not stained, clear ripples but not demon" symbolizing the noble character. Therefore, various utensils are often decorated with lotus patterns. At the same time, it is accompanied by good wishes of 莲(连)生贵子 (means the couple can always give birth to noble sons) and 莲莲(年年) 有余 (every year have enough things to spend). For example, chrysanthemum, the hermit of flowers, who "not prefer chrysanthemum among flowers, and this flower blooms without flowers." Its decorative patterns began to increase in the Song Dynasty. Censers made from Yaozhou kilns, Cizhou kilns, and Ding kilns are mostly accompanied by chrysanthemum patterns. On the other hand, the censer is influenced by the thought of imperial power: the dragon is the incarnation of the emperor, the god, and the symbol of power. Therefore, the decoration of the porcelain censer often appears with the dragon pattern and the Kui (a one-legged monster in fable) pattern. Finally, the patterns of the censer also permeate religious thought: it is said that after the birth of the Buddha, the Buddha took seven steps to grow lotus every step, so the ancients often used the overturned lotus to decorate the utensils, symbolizing the light of Buddha[3]. For example, the lotus petal pattern stove of Chaozhou kiln in Song Dynasty, its whole body is decorated with lotus pattern, reflecting strong religious thought.

Marx once said: "The appearance of art guides its own accidents through itself, and guides it to express something spiritual" [4]. According to the above introduction to the decorative patterns of porcelain censers, it can be found that the decorative patterns of porcelain censers in Song Dynasty are not only a special language, but also beautify the shape of the vessel. At the same time, the censers also reflect people's inner expectations for beauty and the implied meaning of the times.

\section{THE PENETRATION OF SONG NEO-CONFUCIANISM'S STUDY ON PORCELAIN CENSER DECORATION}

Neo-Confucianism was a major achievement of philosophy in the Song Dynasty. On the basis of absorbing the ideas of Buddhism and Taoism, Confucianists in the Song Dynasty made a new interpretation, development and reconstruction of classical Confucianism, and founded neoConfucianism [5]. Under the influence of neoConfucianism, the craftsmen brought "neoConfucianism" into the creation of the censer, and 
formed "Tao and vessel as one" style as Cheng Hao said: "The metaphysical is the Tao, and the metaphysical is the implement. It must be said that the vessel is also the Tao, and the Tao is also the vessel."[6] The abstract "Tao" is embodied in the concrete "vessel", which is the process of perfect combination of art and morality.

When the style of neo-Confucianism prevailed in the Song Dynasty, Taoism was greatly admired by the emperor. Taoism pursued the concepts of "quietness as a refuge" and "clearness and retreat", and advocated nature, pursuit of elegance, and minimalist style, which coincided with the cyan's resentment and tranquil aesthetic appeal. Therefore, the utensils fired in the Official, $\mathrm{Ru}$, Jun, Ge, Yaozhou, Dong, Longquan and other kilns of the Song Dynasty are all based on cyan color. In the Qing Dynasty Lan Pu's "Jingdezhen Taolu • Volume Nine": "Later, although the Song ware had various colors, $\mathrm{Ru}$ porcelain was burnt in Song Dynasty with a light blue color. The official kiln and Ge kiln used powder blue as the top, and the Dong kiln and Longquan were all blue..."[7]. It can be found that Song people have a very high degree of love for cyan. It is precisely because of this that a lot of crystal-like textures and jade-like censer designs have been created. For example, the three-legged kiln of Longquan kiln achieves the artistic effect of enamel beauty like sapphire. The combination of cyan enamel decoration and neo-Confucianism creates a quiet and harmonious taste.

The people of Song Dynasty also paid attention to the neo-Confucianism of "in harmony and majesty, pursuing tranquility and elegance", which made the porcelain of the Song Dynasty mainly decorated with simple elegance. Porcelain censers also follow this principle in design. The sky blue of Ru porcelain, the plain white of Ding kiln, the run jade of the Official kiln, and the blue green of the Longquan kiln that people have seen are all based on the elegant single glaze decoration. Coupled with simple decorative techniques such as engraving and drawing flowers, and decorative patterns such as swirling patterns as a foil, the "elegant" culture is fully displayed on the censers.

\section{THE EMBODIMENT OF ARTISTIC STYLE IN THE DECORATION OF PORCELAIN CENSERS}

\subsection{Distinctive Local Characteristics}

The decoration of porcelain censers in the Song Dynasty showed obvious regional characteristics during the two Song Dynasties. From the perspective of glaze decoration, the celadon censers of Ru kiln in the north were more famous. According to the Southern Song Dynasty Zhou Hui's "Qingbo Records" recorded: "Ru kiln, it is forbidden to burn in the palace, and the agate powder is glaze inside. It is only for the imperial picking and retreat, which is especially rare." [8] The agate powder is developed as a glaze and applied to the censers to make the glaze appear crystal clear. It is really wonderful; compared to the northern Ru kiln celadon censers, the glaze of the southern Longquan kiln censer is not inferior to this. It has the characteristics of "thick as cream, greener than beautiful jade", and is famous for its "pink green" and "plum green". The deep and elegant pink green, plum green jade texture, such a graceful texture, is deeply loved by literati. The famous poet of the Southern Song Dynasty, Yang Wanli, once praised the beauty of the glaze of the Longquan kiln censers in "Burning Incense": 环瓷作鼎 碧于水, 削银为叶轻如纸 (The glaze is greener than water, and the silver is cut into leaves as light as paper)"[9]. From the perspective of decorative techniques and patterns, the northern kilns represented by Cizhou kiln use decorative techniques such as picking, engraving and scratching, as well as decorative patterns such as flowers and birds; the southern Jizhou kiln censers combined engraving, scratching and painting, and also created a decorative technique of paper-cutting and decals. The decorative patterns are mainly plants, flowers, birds and beasts, supplemented by fret patterns, wishful cloud patterns, etc., making the censers simple and elegant, with strong local characteristics and artistic style. Generally speaking, porcelain censers from north to south have their own local characteristics. Generally speaking, the overall design of censers calcined in the south will show a delicate and beautiful beauty, while in the north it will show a sense of straightforwardness. It is precisely because the decorative art style of the porcelain censers of the Song Dynasty has obvious regional characteristics that it occupies an important place in the history of Chinese censers, leaving its unique historical mark, so that later generations are keen on collecting and studying.

\subsection{Strong Antique Tendency}

In the Song Dynasty, with the unearthing of cultural relics from the pre-Qin period such as bronzes, ceramics, and lacquerware, it coincided with the rise of epigraphy, which set off an antique style with an increasingly strong feeling, which pushed the antique to glory. The censer, a necessity in the life of 
the Song people, has become the best choice for antiques, especially the porcelain censers, which has been made into three-legged censers, tripod censers, pot-like censers and case-like censers. From the palace to the folk, all kinds of kilns are competing for production, such as Ding kiln, Jun kiln, Longquan kiln, Yaozhou kiln, etc. It can be seen how widespread the antique style is and how deep the awareness is.

The decorative arts of the Song Dynasty actually depend on simplicity, elegance, simplicity, and practicality. There are few complicated decorations, and they pursue a kind of plain beauty. Based on this artistic style, when they treated artifacts from the preQin period, they did not imitate everything mechanically. The craftsmen have their own ideas. They refined the complicated shapes of utensils, simplified the decoration techniques on the surface of the censers, and used their proficient craftsmanship to create porcelain censers that belong to the aesthetic style of the Song Dynasty. Taking the Jin Yaozhou kiln Kui dragon pattern three-legged furnace as an example ("Figure 3"). Although the shape imitates the bronze tripod, it is completely different from the tripod in terms of glaze color, decoration and technique. The glaze color is clear and natural, and the waist and abdomen are decorated with a lotus petal pattern with a 回 pattern. The decoration techniques are carved, scratched, and piled. Three legs are decorated with tiger heads and tiger claws, which are very vivid. In a nutshell, the Song Dynasty antique censers not only inherited the essence of ancient utensils, but also integrated the aesthetics of the dynasty.

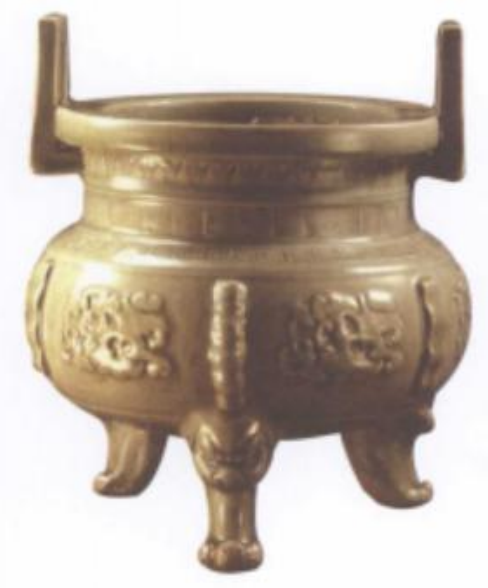

Figure 3 Jin Yaozhou kiln Kui dragon pattern threelegged furnace.
It is precisely because of the strong sense of antiques in the artistic tendency of the Song Dynasty that such a colorful and exquisite censer was created, which injected a new era atmosphere into the traditional utensils, and at the same time left precious wealth for future generations to study the history of censers.

\section{CONCLUSION}

The development of Song neo-Confucianism studies has achieved the artistic style of Song Dynasty porcelain censers decoration with local characteristics and antique tendencies, and has nurtured natural, plain, and elegant social customs and aesthetic connotations. Together, they have tainted the natural and natural glaze color of the porcelain censers of the Song Dynasty, mature and exquisite techniques, and decorative patterns that mean beyond the image, etc., adding a strong stroke to the history of censers, which also provides historical reference for the development and innovation of decorative art of future generations of censers.

\section{AUTHORS' CONTRIBUTIONS}

Xuemei Liu is responsible for writing the first draft, and Yihong Yuan is responsible for polishing and editing the paper.

\section{REFERENCES}

[1] Qian Handong, Cultural Reminiscenes — The Glorious Glimmer of Ceramic Censers [M]. Shanghai: Shanghai Culture Publishing House, 2009, 01. (in Chinese)

[2] Paopaozhou, Song People's Grace and Life [EB/OL].(2009.09.01).[2020.09.29].

http://www.360doc.com/content/19/0901/16/31 072807_858483115.shtml. (in Chinese)

[3] Du Wen, Appreciation of Yaozhou Kiln's Buddhism Culture Theme Ceramics (Part 2) [J]. Collection World, 2005(10): 78-80. (in Chinese)

[4] Guo Xiaodong, "Inborn Nature" and "Heavenendowed Nature"— On Cheng Ming-dao's Study of "Nature" [J]. Fudan Journal(Social Sciences Edition), 2004(01): 92-98+106. (in Chinese)

[5] Gao Jinpeng, Song Porcelains Modeling Arts Research [D]. Jingdezhen Ceramic Institute, 2011. (in Chinese) 
[6] He Bowen, Embracing the Censer - A Study of the Censers of Song Dynasty [D]. China Academy of Arts, 2010. (in Chinese)

[7] Li Gang, The Study on the Secret of "Secret Color Porcelain" [J]. Cultural Relics of the East, 2005 (04): 6-15. (in Chinese)

[8] Yang Junyi, Preliminary Study on Ru Kiln [J]. China Ceramics, 2013, 49(06): 74-76. (in Chinese)

[9] Lei Guoqiang, Li Zhen, Appreciation and Research on Longquan Celadon Incense Burner in Southern Song Dynasty (Part Two) [J]. Oriental Collection, 2015(02): 54-59. (in Chinese)

[10] $\mathrm{Hu}$ Xizhen, On the Decorative Art of Song Dynasty Porcelain [D]. Chongqing Normal University, 2007. (in Chinese)

[11] Ge Yonghuan, Exploration of the Beauty of Tang and Song Ceramic Decoration Art [J]. Art Panorama, 2016(07): 101. (in Chinese)

[12] Peng Siti, Song Dynasty Incense Burner Special Shape and Aesthetic Implication Revisited [D]. Guangzhou University, 2017. (in Chinese)

[13] Wei Jie, Research on the Tang and Song Dynasty Censer Design [D]. Jiangnan University, 2017. (in Chinese)

[14] Yu Jie, Studies Towards Song Dynasty's Censers Design Affected by Interests of Literati [D]. Jiangnan University, 2015. (in Chinese)

[15] Xu Lu, Research on Incense Burner in Song Dynasty [D]. Shanghai: Shanghai University, 2010. (in Chinese)

[16] Zhu Xirui, Zhong Dan, Jiang Xiaolan, On the Aesthetic Characteristics of Ceramic Incense Burner in the Song Dynasty [J]. Ceramic Studies Journal, 2009, 24(04): 63-64. (in Chinese) 